\title{
Peyronie's disease: Review of the pathology and current events in treatment
}

\author{
Luis D. Carrillo-Córdova*, Edson D. Rodríguez-Valle, Jonathan A. Rodriguez-Robles, \\ Jhonatan Vitar-Sandoval, Daniel Calvo-Mena, Noe Garduño-Segovia, Samuel Aguilar-Aizcorbe, \\ Adair Reyes-Sánchez, Christian Acevedo-Garcia, Jorge Jaspersen-Gastelum and \\ Mario S. Almanza-Gonzalez \\ Departamento de Urología, Hospital General de México “Dr. Eduardo Liceaga”, Mexico City, Mexico
}

\begin{abstract}
Peyronie's disease is a medical condition characterized by an abnormal curvature of the penis, which presents a poorly understood pathophysiology, featuring abnormal fibroblasts of the tunica albuginea secondary to trauma or stemming from congenital causes. Currently, there are multiple therapeutic options, such as oral pharmacological treatments that either report poor results or partial improvements, as well as intralesional therapies viewed as controversial and surgery as a therapeutic choice. However, this can be implemented once the disease is in its stable phase. A number of alternatives can be elected regarding the needs and symptoms of patients.
\end{abstract}

Key words: Peyronie's disease. Medical treatment. Surgical treatment

\section{Introduction}

Peyronie's disease (PD) is a connective tissue disease that primarily affects the tunica albuginea of the corpora cavernosa of the penis. François De La Peyronie (1678-1747) first described this disease in a medical treatise addressing ejaculatory failure. It usually presents with a palpable induration of the penis, which causes deformity during erection.

The formation of fibrous plaques in the tunica albuginea and surrounding cavernous tissue alters the anatomy and causes deformities of the penis that is acquired during erection with different degrees of flexion and narrowing of the circumference of the MIMO. This condition can occur with or without pain and can cause erectile dysfunction. Currently, therapy remains a controversial matter. There is no consensus on the utility of medical and surgical treatment. This article aims to conduct a systemic review of PD and discuss currently available treatments.

\section{Definition}

PD is a congenital or acquired penile abnormality, which is characterized by fibrosis of the tunica albuginea ${ }^{1}$. The fibrous tissue in the tunica albuginea prevents the expansion of the latter during erection, resulting in shortening, flexion, and pain of the penis, which is associated with sexual dysfunction² (Fig. 1).
Correspondence:

*Luis D. Carrillo-Córdova

E-mail: carrillocor@gmail.com
Available online: 17-10-2019 Rev Med Hosp Gen Mex. 2019;82(3):208-214 www.hospitalgeneral.mx 0185-1063/@ 2017 Sociedad Médica del Hospital General de México. Published by Permanyer México SA de CV. This is an open access article under the CC BY-NC-ND license (http://creativecommons.org/licenses/by-nc-nd/4.0/). 


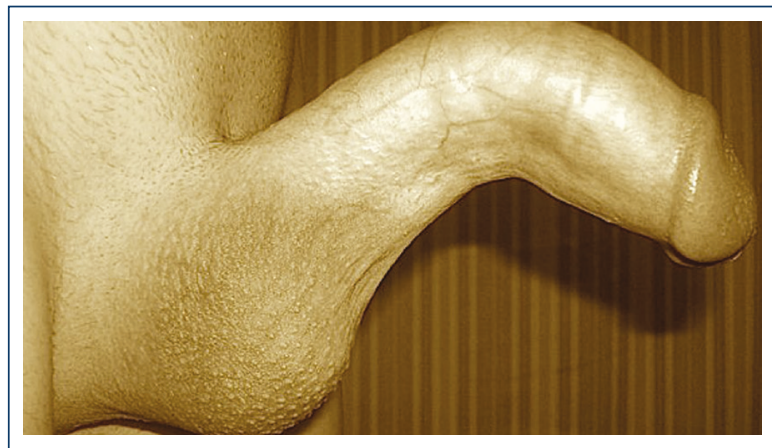

Figure 1. Clinical presentation of PD.

A ventral defect is observed in the tunica albuginea, causing a pathological curvature of the distal end of the penis.

\section{Pathophysiology}

The development mechanism of PD is unknown. However, one of its causes can be due to a prolonged and sustained inflammatory response, triggered by trauma, which allows extravascular protein deposition, inflammatory cell recruitment, fibrin deposition on the expression of inflammatory cytosines, and release of elastase $^{1}$, which leads to a change of type I collagen into type III collagen. Overexpression of transforming growth factor (TGF)-B and interleukin (IL)- 6 has been reported together with a lower number of blood vessels and reduced apoptosis in the histopathological samples of patients with $\mathrm{PD}^{3}$.

Currently, the active role of free radicals is recognized as inducing an important inflammatory response, favoring the first stage of this disease. There is an important expression of pro-inflammatory and pro-fibrotic cytosines, with subsequent activation of the NF-kB factor ${ }^{4}$.

Another hypothesis states that it is a scar tissue disorder developed by genetic susceptibility, based on documentary evidence of variations in the TGF-beta 1 gene and expression of SMAD transcription factors, which regulate the mechanisms of fibrosis ${ }^{2}$. The histological features of PD show lymphocytic and plasmacytic infiltrate of the tunica albuginea, as well as of the erectile tissues (Fig. 2$)^{3}$.

\section{Epidemiology}

PD mainly affects men aged between 40 and 70 years, mostly of Caucasian origin, with a prevalence of 0.4 $9 \%$, and an incidence of $0.39-3 \% 3,4$. The risk factor that is majorly associated with PD is trauma. Other associated factors to a lesser extent are peripheral vascular

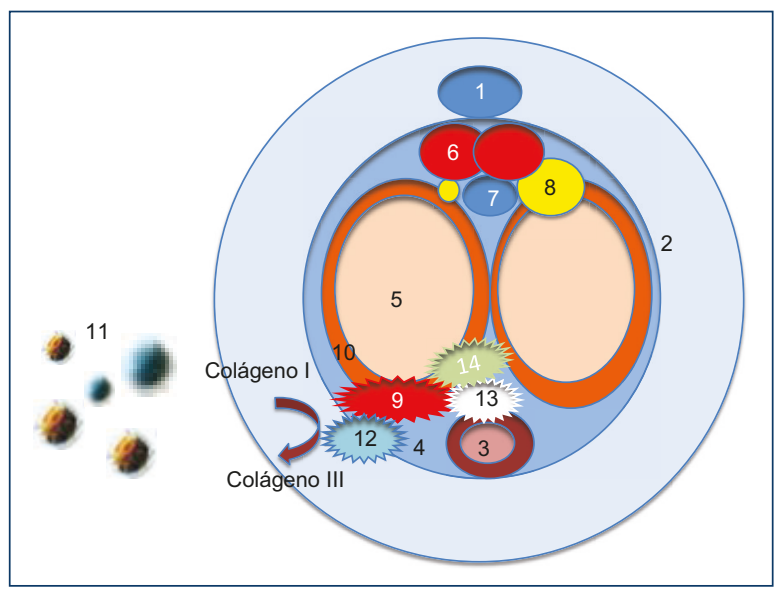

Figure 2. Peyronie's disease pathophysiology.

1: dorsal vein of the penis, 2: skin, 3: urethra, 4: Buck's fascia, 5: cavernous body, 6: dorsal artery, 7: deep dorsal vein, 8: dorsal nerve of the penis, 9: defect in the tunica albuginea, 10: tunica albuginea, 11: $T$ and B lymphocytes, 12: fibrin deposit, 13: cytosine overexpression,

14: elastase release.

disease, smoking, alcoholism, and some invasive urological procedures (transurethral resection of the prostate and cystoscopy $)^{5}$. Other studies comment on an inverse relationship, with high LDL levels and abdominal circumference, treatment with thiazides and Dupuytren's disease ${ }^{4}$.

\section{Diagnostic approach}

A thorough enquiry and physical examination should be performed for a basic evaluation, with an artificially induced erection to measure and document the degree of curvature, as well as document the fibrous plaque by ultrasound scan, if such procedure is available. Patient information should also be collected about the onset of the disease and duration, a history of trauma to the genitals and perineum, the development of penile deformity, curvature, penis shrinkage, erectile dysfunction, and subjective evaluation of the erectile and sexual function?

\section{Clinical presentation}

We usually come across patients in their fifties, with a recent onset of curvature in the penis, which is related to mild to moderate pain. The erection is not affected at the beginning. However, the curvature can bring difficulties in sexual activity. It is worth mentioning that abnormalities in the flaccid penis are not palpable 1. During the course of the disease, it can be classified as active and stable. 
Table 1. Pharmacological treatment of PD

\begin{tabular}{|c|c|c|}
\hline Pharmaceutical drug & Mechanism of action & Utility \\
\hline Vitamin $\mathrm{E}$ & Reduction of free radicals & No evidence of its utility ${ }^{1}$ \\
\hline Potaba & Inhibits the secretion of glycosaminoglycans & Decreases plaque size, without impact on curvature ${ }^{2,3}$ \\
\hline Tamoxifen & $\begin{array}{l}\text { Decreases fibrogenesis in the tunica } \\
\text { albuginea }\end{array}$ & No improvement in plaque or curvature ${ }^{2}$ \\
\hline Colchicine & $\begin{array}{l}\text { Inhibits collagen deposition and decreases } \\
\text { TGF-beta } 1 \text { expression }\end{array}$ & Decreases plaque size, without changes in curvature ${ }^{2,3}$ \\
\hline Carnitine & Acetyl-CoA carboxylase inhibitor & Reduces pain, curvature, and stops progression ${ }^{3}$ \\
\hline L-Arginine & cGMP increase & $\begin{array}{l}\text { In animal models, it decreases the size of the fibrous } \\
\text { plaque and the expression of type I collagen }{ }^{2}\end{array}$ \\
\hline Pentoxifylline & Nonselective phosphodiesterase inhibitor & $\begin{array}{l}\text { Chronic disease improves curvature and plaque } \\
\text { volume }^{2}\end{array}$ \\
\hline Corticosteroid & Immune response & No improvement ${ }^{1}$ \\
\hline $\begin{array}{l}\text { Collagenase clostridium } \\
\text { histolyticum }\end{array}$ & Interstitial collagen degradation & Decreases curvature, prevents progression ${ }^{2}$ \\
\hline Interferon alfa-2b & $\begin{array}{l}\text { Inhibits the production of fibroblasts and } \\
\text { collagen }\end{array}$ & reduces plaque size and pain $n^{1,14}$ \\
\hline Verapamil & Calcium channel blocker & No clinical improvement ${ }^{2}$ \\
\hline
\end{tabular}

PD: Peyronie's disease; TGF: transforming growth factor.

Pain or discomfort is reported in the active presentation, with or without an erection, associated with a history of penile injury during sexual activity, although most patients do not remember any incident. The erection may be intact or compromised. The disease stabilizes once no changes in symptomatology are reported within at least 3 months. This generally occurs around 12-18 months after the onset of symptoms. Pain rarely occurs and when it does, it is typically of mild intensity. The plaque is palpable or evident on ultrasound scans with an obvious deformity of the penis ${ }^{1}$.

Over time, the penile curvature will get worse in about $30-50 \%$ of patients with PD and will stabilize in $47-67 \%$ of cases. Pain occurs in about $35-45 \%$ of patients at an early stage of the disease and subsides in about $90 \%$ of cases at 12 months after the presentation of symptoms ${ }^{6}$. As for findings, comments during medical examinations state that $100 \%$ of the patients presented induration, $83 \%$ presented induration accompanied by angulation, $46 \%$ presented induration accompanied by pain, and only $32 \%$ of patients presented induration, angulation, and pain ${ }^{7}$.

\section{Treatment}

There are several types of treatment for PD, which must be chosen with moderation and according to the needs and response of the patient. In general, approaches to treatment should range from less to more invasive ones. Patients with active disease, instability or progression of the deformity should receive conservative treatment, as well as patients with painful erections (particularly on palpation) or those who are not interested in surgical treatment ${ }^{8}$.

Surgical treatment is recommended to those patients who have presented symptoms for at least 12 months or patients whose penile curvature or deformity has become stable for at least 3 months ${ }^{1}$. The invasive approach can also be offered to those who have not had a response to medical treatment; patients with unsatisfactory intercourse or those who desire faster results ${ }^{2}$. In its acute phase, nonsteroidal anti-inflammatory drug analgesics are recommended for pain management. Table 1 shows a summary of pharmacological treatment for PD.

\section{Oral treatments}

\section{Vitamin E}

A fat-soluble vitamin that acts as a natural antioxidant reducing the number of free radicals produced during metabolism. There is no evidence supporting its utility or demonstrating its therapeutic benefit in $\mathrm{PD}^{9}$. However, it is frequently prescribed due to its low cost, easy 
availability, minimal adverse effects, in addition to its placebo effect ${ }^{10}$.

\section{Potaba}

Potassium paraminobenzoate has anti-inflammatory and antifibrous properties, inhibiting the secretion of glycosaminoglycans by fibroblasts and stabilizing serotonin monoamine oxidase activity. Several studies have evidenced improvement in plaque size after 12 months, and improvement in pain, without having an effect on pre-existing curvature ${ }^{11}$.

\section{Tamoxifen}

Is an estrogen receptor antagonist whose mechanism of action in the tunica albuginea is the reduction of the fibrogenesis by the modulation of the release of TGF-beta 1. However, it does not generate significant improvement in pain management, penis curvature, or size ${ }^{12}$.

\section{Colchicine}

It reduces the contraction of wounds and inhibits collagen deposition by decreasing the expression of TGF-beta $1^{13}$. Some studies comment that it helps in the management of pain in $95 \%$ of patient's decreases curvature in $30 \%$ of patients ${ }^{14}$ and decreases the density of the fibrous plaque in approximately $50 \%$ of patients ${ }^{6}$. Other contrast studies reveal that no significant difference has been demonstrated when compared to placebo trials ${ }^{15}$.

\section{Carnitine}

An Acetyl-CoA carboxylase inhibitor, which has anti-inflammatory properties ${ }^{16}$, presents greater benefits compared to tamoxifen in reducing pain, curvature, and stops progression though it does not reduce plaque size ${ }^{6}$.

\section{L-Arginine}

A nitric oxide precursor and its anti-inflammatory mechanism is assumed as due to the increase in cGMP. In animal models, it reduces the size of the fibrous plaque and the expression of type I collagen, although no studies have been conducted in humans ${ }^{17}$.

\section{Pentoxifylline}

Is a non-selective phosphodiesterase inhibitor that restricts fibroblast proliferation, it also contributes by the diminishment of collagen deposits and eslastogenesis $^{18}$. It improves curvature and plaque volume in patients with chronic disease ${ }^{19}$. It is also believed to stabilize or reduce calcium content in the plaque ${ }^{20}$.

\section{Intralesional treatment}

\section{Corticosteroids}

Corticosteroids have an anti-inflammatory effect secondary to suppressing the immune response. Nonetheless, several studies state that it does not present statistically significant evidence for its administration ${ }^{21}$.

\section{Collagenase clostridium histolyticum}

Its mechanism of action is through the degradation of interstitial collagen ${ }^{2}$. It should be administered in patients with stable disease and/or curvature between $>30^{\circ}$ and $<90^{\circ}$ and intact erectile function ${ }^{1}$. It reduces penile curvature in patients with the curvature of $30^{\circ}$. $90^{\circ}$, patients who present more than 2 years of evolution, those who do not develop plaque calcification and patients who have an IIEF $>17$. It is thought to reduce sexual activity difficulties in patients with penile curvature ranging from $30^{\circ}$ to $60^{\circ}$, disease history of more than 4 years of evolution, non-calcified plaque, IIEF $1-5$, and IIEF $>17^{22}$. Important complications have been reported after the application of this treatment, such as penile hematoma and fracture, detected in up to $10 \%$ of patients ${ }^{23}$.

\section{IL alpha-2b}

IL alpha-2b regulates the immune response, inhibiting the production of fibroblasts and collagen, in addition to increasing collagenase activity. One study reports that it reduces plaque size in $13.5 \%$ of patients, and pain in $67.7 \%{ }^{1}$. Another study reveals that sexual function improves in $30 \%$ of patients ${ }^{24}$.

\section{Verapamil}

Is a calcium channel blocker that contributes on the regulation of the inflammatory response and fibroblast proliferation ${ }^{25}$. However, it does not generate a significant difference with respect to the placebo effect, when plaque size, pain, penile curvature, and sexual function were compared ${ }^{3}$. One study reports that patients treated with intralesional verapamil for control purposes showed a decrease in plaque size in $17.5 \%$ of patients, 
pain reduction in $30 \%$, reduced curvature in $17.5 \%$, and improvement in sexual function in $5 \%$ of patients. One study states that topical verapamil applied for 9 months decreases penile curvature in $61.1 \%$ of participants, with plaque size reduction in $84 \%$ of them, pain reduction in $100 \%$, and improvement in the quality perception of erection in $81 \%$ of patients ${ }^{26}$.

\section{Hyaluronic acid}

The use of hyaluronic acid has been recently described. Several intra-lesion therapeutic protocols have been proposed for the treatment of PD. A recent study compared the effectiveness of verapamil against hyaluronic acid, stating that the hyaluronic acid group had a greater decrease in curvature and better patient acceptance ${ }^{27}$.

\section{Non-pharmacologic treatment Stem cells}

Stem cells prevent fibrosis, inducing immunomodulation, which produces phenotypic changes of fibroblasts. Some experiments have been conducted in animal models with induction, where stem cells are applied during its acute phase. These have prevented the development of plaque formation, though there are no studies evidencing its efficacy and safety in humans. Stem cells that have shown greater benefits in animal models are those derived from the adipose tissue. More prospective studies in humans are necessary for a thorough understanding of this therapeutic tool ${ }^{28}$.

\section{Radiotherapy}

Radiotherapy has been used for a long time for PD management because it was thought to help fibrous plaque degeneration. However, all current recommendations contraindicate it ${ }^{29}$.

\section{Vacuum pump}

It presents clinical and statistically significant improvement as PD therapy. Its effectiveness was evaluated in a study where it is commented that $67 \%$ of the participants reported a decrease in penile curvature, $10 \%$ had an increase in curvature, and $23 \%$ of participants did not present any modifications. In addition, $51 \%$ of participants declared that they were satisfied with the results, though other participants required surgical procedures. It is concluded that the vacuum pump improves or stabilizes the curvature of the penis, reducing the need for surgical treatment ${ }^{30}$.

\section{Extracorporeal shockwave therapy (ESWT)}

ESWT is viewed as effective for pain management and improvement of sexual function ${ }^{31}$ but should not be used to reduce curvature or plaque size ${ }^{1}$. A study commented that $85 \%$ of the participants reported improvement in pain symptoms compared to $48 \%$ of participants in the control group. Deviation worsened in $40 \%$ of participants and only in $24 \%$ of the control group patients. An increase in plaque size was found in $10 \%$ of the participants, with no patients in the control group reporting an increase in plaque size ${ }^{31}$.

\section{Surgical treatment}

Surgical treatment is aimed to correct penile curvature or deformity, by preserving or restoring erectile function and preventing shrinkage or loss of girth ${ }^{2}$. The most common inclusion criterion for performing the surgical treatment is that 12 months must have elapsed from the onset of symptoms and evidence of stable curvature for at least 3 month $^{6}$. In addition, it can also be offered to those patients who do not have satisfactory intercourse, present failure in conservative treatment and those seeking quicker results ${ }^{6}$.

Some studies comment that conservative treatments of PD are useful for improving pain during erection, but only a small percentage of patients experience penis straightening ${ }^{6}$. There are multiple surgical techniques described for PD correction; however, the most used and most frequently cited are tunical plication, enlargement of the tunica albuginea (incision or excision) and the use of penile prosthesis ${ }^{2}$.

\section{Tunical plication}

Tunical plication is the most commonly used technique, representing approximately $50 \%$ of all surgeries performed for PD. It is used in patients whose erection is suitable for intercourse or who have erectile dysfunction that responds to medications or vacuum pump 1 .

The Nesbit technique is the most commonly used technique, which involves the excision of a portion of the tunica albuginea on the contralateral side of the curvature $^{32}$. This procedure may result in a decrease in penis size ${ }^{2}$. Studies state that the direction and degree of curvature before surgery predicted this decrease in 
penis size ${ }^{33}$. A retrospective analysis was conducted in 52 patients undergoing penile plication for the treatment of PD or congenital curvature of the penis. This analysis was compared with techniques that involved degloving or not. Surgical success rates, complications, and patient satisfaction were evaluated with the treatment benefit scale. The overall surgical success rate was $92.3 \%$, with an average follow-up of $18.84 \pm 23.51$ months. There were no intraoperative complications. In the degloving group, $42.6 \%$ of the patients were very satisfied and $42.6 \%$ reported better results. In the group that did not undergo degloving procedures, $61.5 \%$ of the patients were very satisfied and $30.8 \%$ reported better results. The comparison of the results was not statistically significant between the groups ${ }^{34}$. Currently, this technique is widely used because it is simple, minimally invasive, and preserves sexual function. However, it decreases penis size and does not correct the hourglass defect or hinge effect ${ }^{2}$.

\section{Enlargement of the tunica albuginea}

It is used in patients with adequate erection for intercourse and severe deformity (curvature $>60^{\circ}$, or articulation with severe plaque calcification) $)^{2}$. The most commonly used procedures for tunica albuginea enlargement include partial excision or incision and grafting. Partial excision has displaced complete excision because the latter is greatly associated with erectile dysfunction, and even partial excision can improve sexual function ${ }^{35,36}$.

The cut is made in the area of maximum curvature, using a double-Y or $\mathrm{H}$ incision ${ }^{37}$. The grafts commonly used are obtained from the dermis, saphenous vein, oral mucosa, proximal crura, tunica vaginalis, dura mater, temporal fascia, and fascia lata ${ }^{38}$. Synthetic grafts such as Dacron and polytetrafluoroethylene are currently used ${ }^{39}$. Recent studies comment that this surgical technique helps to straighten the penis in $80-100 \%$ of patients. The most frequently encountered complications are hypoesthesia, persistent or recurrent curvature, and erectile dysfunction ${ }^{6}$.

\section{Penile prosthesis}

It is used in patients with PD that have erectile dysfunction and/or sufficient deformity to prevent intercourse despite oral medication or vacuum pump ${ }^{1}$. It is also used in patients who present a complex deviation that cannot undergo corporoplasty or grafting to improve shrinkage ${ }^{40}$. Two types of prostheses are most frequently used, malleable prostheses and inflatable prostheses. The most accepted in the management of patients with PD are inflatable prostheses due to better sexual satisfaction for the patient, less residual curvature, and successful straightening ${ }^{41}$. An inflatable prosthesis can be used as an effective corrective tool in patients with an unstable penis due to indentation or hourglass deformity and minimal curvature ${ }^{3}$.

If proper straightening is not achieved with the use of inflatable prostheses, the first step is the manual modeling of the penis ${ }^{2}$. In case of failure of this penile straightening method, the next step is plication, with multiple incisions in the tunica albuginea or excision with or without graft 39,42 . The most commonly presented complications are penis shrinkage, hypoesthesia, paresthesia, difficulties in inflating and deflating the device, mechanical failure, erosion, and infections ${ }^{43}$.

\section{Conflicts of interest}

The authors have not reported any conflicts of interest.

\section{Ethical disclosures}

Protection of human and animal subjects. The authors declare that the procedures followed were in accordance with the regulations of the relevant clinical research ethics committee and with those of the Code of Ethics of the World Medical Association (Declaration of Helsinki).

Confidentiality of data. The authors declare that they have followed the protocols of their work center on the publication of patient data.

Right to privacy and informed consent. The authors have obtained the written informed consent of the patients or subjects mentioned in the article. The corresponding author is in possession of this document.

\section{References}

1. Nehra A, Alterowitz R, Culkin DJ, Faraday MM, Hakim LS, Heidelbaugh JJ, et al. Peyronie's disease: AUA guideline. J Urol. 2015;194:745-53.

2. Yafi FA, Pinsky MR, Sangkum P, Hellstrom WJ. Therapeutic advances in the treatment of Peyronie's disease. Andrology. 2015;3:650-60.

3. Watanabe MS, Theodoro TR, Coelho NL, Mendes A, Leonel MLP, Mader AM, et al. Extracellular matrix alterations in the Peyronie's disease. J Adv Res. 2017;8:455-61.

4. Paulis G, Romano G, Paulis L, Barletta D. Recent pathophysiological aspects of Peyronie's disease: role of free radicals, rationale, and therapeutic implications for antioxidant treatment-literature review. Adv Urol. 2017;2017:4653512.

5. Bjekic MD, Vlajinac HD, Sipetic SB, Marinkovic JM. Risk factors for Peyronie's disease: a case-control study. BJU Int. 2006;97:570-4.

6. Hatzimouratidis K, Eardley I, Giuliano F, Hatzichristou D, Moncada I, Salonia $A$, et al. EAU guidelines on penile curvature. Eur Urol. 2012;62:543-52. 
7. Sommer F, Schwarzer U, Wassmer G, Bloch W, Braun M, Klotz T, et al. Epidemiology of Peyronie's disease. Int J Impot Res. 2002;14:379-83.

8. Levine LA. Peyronie's disease: a contemporary review of non-surgical treatment. Arab J Urol. 2013;11:278-83.

9. Pryor J, Farell C. Controlled clinical trial of Vitamin E in Peyronie's disease. Prog Reprod Biol. 1983;9:41-5

10. Hellstrom WJ. Medical management of Peyronie's disease. J Androl. 2009;30:397-405.

11. Weidner W, Hauck EW, Schnitker J, Peyronie's Disease Study Group of Andrological Group of German Urologists. Potassium paraaminobenzoate (POTABA) in the treatment of Peyronie's disease: a prospective, placebo-controlled, randomized study. Eur Urol. 2005;47:530-5.

12. Teloken C, Rhoden EL, Grazziotin TM, Ros CT, Sogari PR, Souto CA, et al. Tamoxifen versus placebo in the treatment of Peyronie's disease. J Urol. 1999;162:2003-5.

13. El-Sakka AI, Bakircioglu ME, Bhatnagar RS, Yen TS, Dahiya R, Lue TF et al. The effects of colchicine on a Peyronie's-like condition in an animal model. J Urol. 1999;161:1980-3.

14. Akkus E, Carrier S, Rehman J, Breza J, Kadioglu A, Lue TF, et al. Is colchicine effective in Peyronie's disease? A pilot study. Urology. 1994;44:291-5.

15. Safarinejad MR. Therapeutic effects of colchicine in the management of Peyronie's disease: a randomized double-blind, placebo-controlled study. Int J Impot Res. 2004;16:238-43.

16. Gur S, Limin M, Hellstrom WJ. Current status and new developments in Peyronie's disease: medical, minimally invasive and surgical treatment options. Expert Opin Pharmacother. 2011:12:931-44.

17. Valente EG, Vernet D, Ferrini MG, Qian A, Rajfer J, Gonzalez-Cadavid NF, et al. L-arginine and phosphodiesterase (PDE) inhibitors counteract fibrosis in the Peyronie's fibrotic plaque and related fibroblast cultures. Nitric Oxide. 2003:9:229-44.

18. Shindel AW, Lin G, Ning H, Banie L, Huang YC, Liu G, et al. Pentoxifylline attenuates transforming growth factor- $\nabla 1$-stimulated collagen deposition and elastogenesis in human tunica albuginea-derived fibroblasts part 1: impact on extracellular matrix. J Sex Med. 2010;7:2077-85

19. Safarinejad MR, Asgari MA, Hosseini SY, Dadkhah F. A double-blind placebo-controlled study of the efficacy and safety of pentoxifylline in early chronic Peyronie's disease. BJU Int. 2010;106:240-8.

20. Brant WO, Dean RC, Lue TF. Treatment of Peyronie's disease with oral pentoxifylline. Nat Clin Pract Urol. 2006;3:111-5.

21. Cipollone G, Nicolai M, Mastroprimiano G, lantorno R, Longeri D, Tenaglia $R$, et al. Betamethasone versus placebo in Peyronie's disease. Arch Ital Urol Androl. 1998;70:165-8.

22. Hellstrom WJ, Tan RB, Liu G. Safety profile of collagenase clostridium histolyticum stratified by degree of penile curvature in patients with peyronie disease. Urology. 2017;106:237.e9-2.37E+16.

23. Hobaugh C, Pastuszak AW. Serious complications of collagenase clostridium histiolyticum injection for Peyronie's disease: more than meets the eye! Transl Androl Urol. 2017;6:320-1.

24. Lacy GL $2^{\text {nd }}$, Adams DM, Hellstrom WJ. Intralesional interferon-alpha-2b for the treatment of Peyronie's disease. Int J Impot Res. 2002;14:336-9.
25. Levine LA, Merrick PF, Lee RC. Intralesional verapamil injection for the treatment of Peyronie's disease. J Urol. 1994;151:1522-4.

26. Shirazi M, Haghpanah AR, Badiee M, Afrasiabi MA, Haghpanah S. Effect of intralesional verapamil for treatment of Peyronie's disease: a randomized single-blind, placebo-controlled study. Int Urol Nephrol. 2009;41:467-71.

27. Favilla V, Russo GI, Zucchi A, Siracusa G, Privitera S, Cimino S, et al. Evaluation of intralesional injection of hyaluronic acid compared with verapamil in peyronie's disease: preliminary results from a prospective, double-blinded, randomized study. Andrology. 2017;5:771-5

28. Dellis A, Papatsoris A. Stem cell therapy for the treatment of Peyronie's disease. Expert Opin Biol Ther. 2017:17:407-13.

29. Mulhall JP, Hall M, Broderick GA, Incrocci L. Radiation therapy in Peyronie's disease. J Sex Med. 2012;9:1435-41.

30. Raheem AA, Garaffa G, Raheem TA, Dixon M, Kayes A, Christopher N, et al. The role of vacuum pump therapy to mechanically straighten the penis in Peyronie's disease. BJU Int. 2010;106:1178-80.

31. Shimpi RK, Jain RJ. Role of extracorporeal shock wave therapy in management of Peyronie's disease: a preliminary report. Urol Ann. 2016:8:409-17.

32. Andrews $\mathrm{HO}$, al-Akraa M, Pryor JP, Ralph DJ. The nesbit operation for congenital curvature of the penis. Int J Impot Res. 1999;11:119-22.

33. Greenfield JM, Lucas S, Levine LA. Factors affecting the loss of length associated with tunica albuginea plication for correction of penile curvature. J Urol. 2006;175:238-41.

34. Kadirov R, Coskun B, Kaygisiz O, Gunseren KO, Kordan Y, Yavascaoglu I, et al. Penile plication with or without degloving of the penis results in similar outcomes. Sex Med. 2017:5:e142-e147.

35. Hatzichristodoulou G, Osmonov D, Kübler H, Hellstrom WJG, Yafi FA Contemporary review of grafting techniques for the surgical treatment of Peyronie's disease. Sex Med Rev. 2017;5:544-52.

36. Taylor FL, Abern MR, Levine LA. Predicting erectile dysfunction following surgical correction of Peyronie's disease without inflatable penile prosthesis placement: vascular assessment and preoperative risk factors. J Sex Med. 2012;9:296-301.

37. Gelbard MK. Relaxing incisions in the correction of penile deformity due to Peyronie's disease. J Urol. 1995; 154:1457-60.

38. Kadioglu A, Sanli O, Akman T, Ersay A, Guven S, Mammadov F, et al Graft materials in Peyronie's disease surgery: a comprehensive review. Sex Med. 2007:4:581-95.

39. Levine LA, Burnett AL. Standard operating procedures for Peyronie's disease. J Sex Med. 2013;10:230-44

40. Ateia $\mathrm{AH}$, Voinescu $\mathrm{O}$, Geavlete R. Penile prosthesis in the surgical treatment of Peyronie's disease. J Med Life. 2012;5:280-2.

41. Ghanem HM, Fahmy I, el-Meliegy A. Malleable penile implants without plaque surgery in the treatment of Peyronie's disease. Int J Impot Res. 1998;10:171-3.

42. Yafi FA, Sangkum P, McCaslin IR, Hellstrom WJ. Strategies for penile prosthesis placement in Peyronie's disease and corporal fibrosis. Cur Urol Rep. 2015;16:21.

43. Zaid UB, Alwaal A, Zhang X, Lue TF. Surgical management of Peyronie's disease. Curr Urol Rep. 2014;15:446. 